\title{
ANTIBIOTIC SUSCEPTIBILITY AND ITS GENETIC ANALYSIS OF VIBRIO CHOLERAE NON-O1, NON-O139 FROM ENVIRONMENTAL SOURCES IN LAO PEOPLE'S DEMOCRATIC REPUBLIC
}

\author{
TOMOKO MIYAZATO*, YUICHIRO TAMAKI* ${ }^{*}$, NOIKASEUMSY SITHIVONG ${ }^{\dagger}$, BOUNNANH PHANTOUAMATH $^{\dagger}$, \\ SITHAT INSISIENGMAY ${ }^{\dagger}$, NAOMI HIGA* ${ }^{*}$ CLAUDIA TOMA* ${ }^{*}$ NOBORU NAKASONE* and MASAAKI IWANAGA* \\ Accepted 11, August, 2004
}

\begin{abstract}
In order to determine the epidemiological features of cholera in Lao PDR, the presence of mobile genetic elements such as plasmid, class I integron and SXT element in $V$. cholerae isolated from surface water were examined. Among the 22 strains isolated from 13 distantly separated sampling sites, no mobile genetic elements associated with drug resistance were found reflecting the antibiogram of the strains. Nevertheless, cholera epidemics due to multiple drug resistant $V$. cholerae occurred repeatedly in those areas until 2000.
\end{abstract}

Vibrio cholerae is a natural inhabitant of aquatic environments and is known to be the causative agent of the acute gastrointestinal disease. Transmission of $V$. cholerae is associated with consumption of contaminated water and contaminated foods $[1,2]$. In spite of the importance and success of rehydration therapy for cholera, antimicrobial therapy still plays a critical role because it can reduce the volume of diarrhea as well as shorten the duration of symptoms and the excretion of Vibrios in the stool [3]. The occurrence of antibiotic-resistant strains of $V$. cholerae is being reported with increasing frequency $[2,4,5]$. However, the antibiotic susceptibilities of organisms spatially and temporally fluctuate. These susceptibilities have to be examined in order to achieve a better understanding of the epidemiological features.

In $V$. cholerae, antibiotic-resistant genes have been found on transmissible plasmids [6-8]. Recently, in addition to plasmids, integron and SXT element have also been described as vehicles in the transport of resistance genes [9, 10]. The analysis of antibiotic resistance determinants on these vehicles is being used as an epidemiological tool.

In Lao People's Democratic Republic (Lao PDR), the antibiotic susceptibility pattern of $V$. cholerae $\mathrm{O} 1$ isolated from cholera patients had been monitored for 8 years (1993-2000) [11, 12]. Although the pathogens were sensitive to the therapeutic antibiotics as expected until 1996, the pattern of antibiotic susceptibility began to change in 1998 [11]. We found that strains isolated before 1997 were resistant to streptomycin and harbored class1integron, while strains isolated after 1997 were resistant to chloramphenicol, tetracycline, streptomycin and sulfamethoxazole-trimethoprim and harbored SXT element [13]. In this study, antibiotic susceptibility and the presence of plasmid, class I integron and SXT element were examined in $V$. cholerae strains isolated from surface water in order to determine the epidemiological features of $V$. cholerae in Lao PDR.

A total of 13 surface water samples from branches of the Mekong River were collected in February 2003. This water is used routinely by people living near the river. The sampling sites were located in cholera epidemic areas until 2000, but no cholera patient was found in 2001, 2002 and 2003. Isolation of $V$. cholerae strains from the samples was accomplished by a modification of the method of Wai and colleagues [14]. About $100 \mathrm{ml}$ of each sample water was taken into two sterile bottles containing $100 \mathrm{ml}$ of $2 \%$ alkaline peptone water ( $\mathrm{pH} \sim 9.0 \sim)$. One bottle was supplemented with sodium pyruvate (final concentration at $0.1 \%$ ) or catalase (final concentration at $50 \mathrm{U} / \mathrm{ml}$ ) to stimulate viable-but-nonculturable (VBNC) V. cholerae O1. All samples were incubated for $24 \mathrm{~h}$ at $37^{\circ} \mathrm{C}$, and then cultured on thiosulfate-citrate-bile salt-sucrose (TCBS) agar for selective isolation of Vibrio species. After $24 \mathrm{~h}$ incubation at $37^{\circ} \mathrm{C}$, yellow colonies were extracted from each TCBS agar and identification of isolates was performed by biochemical tests. The colony-growth pattern of the sample cultured in the supplemented media showed no differences from that cultured in a plain alkaline peptone water, and $V$. cholerae O1 was not detected at all. O-antigen was determined by slide agglutination with polyvalent O1, mono-specific Ogawa-Inaba antisera and with specific anti-O139 antisera

\footnotetext{
* Division of Bacterial Pathogenesis, Department of Microbiology, Graduate School of Medicine, University of the Ryukyus.

+ Center for Laboratory and Epidemiology, Ministry of Health, Vientiane, Lao PDR.
} 
obtained commercially (Denka Seiken Co., Tokyo, Japan). A total of 22 strains of $V$. cholerae were isolated. All of these environmental $V$. cholerae isolates were non-O1, nonO139 serotypes, and cholera toxin non-productive.

The minimum inhibitory concentrations (MICs) of nine antibiotics were determined by agar dilution technique according to the specifications of NCCLS [15]. To examine the production of beta-lactamase by ampicillin resistance isolates, clavulanic acid was used at a constant concentration of $4 \mu \mathrm{g} / \mathrm{ml}$ in combination with ampicillin. The susceptibility profiles of $V$. cholerae isolates are given in Table 1. Of the 22 environmental isolates, two were resistant to polymyxin $\mathrm{B}$ alone; one was resistant to polymyxin $\mathrm{B}$ and ampicillin; and 15 were resistant to ampicillin alone. All isolates were highly sensitive to the other antibiotics examined. For all of the ampicillin resistant isolates, clavulanate reduced the level of MICs to the same as that for the susceptible isolates.

Since plasmids are known to encode resistance to betalactams, the presence of plasmid was examined by the modified method of Kado and Liu [16]. Cells were grown on nutrient agar plates overnight at $37^{\circ} \mathrm{C}$. Colonies were scraped from the plates and suspended in $100 \mu \mathrm{l}$ of a solution containing $50 \%$ glucose, $25 \mathrm{mM}$ EDTA and $1 \mathrm{M}$ Tris (pH 8.0). Then $200 \mu \mathrm{l}$ of lysing solution containing $1 \%$ SDS and $0.2 \mathrm{~N} \mathrm{NaOH}$ was added. After lysis, $300 \mu \mathrm{l}$ of phenol-chloroform-isoamylalcohol (25: 24: 1) was added, and the samples were mixed well. After centrifugation, a sample of the supernatant was electrophoresed on a $0.5 \%$ Seakem ME agarose. Shigella flexneri 2a YSH 6000 [17] harboring approximately $230 \mathrm{~kb}$ plasmid was used as the control strain. None of the 16 ampicillin resistant isolates harbored any plasmids (data not shown).

Next, we investigated the presence of class I integron, which has been reported to contain a gene cassette that conferred resistance to beta-lactams [18]. To identify class I integron, primers inDS-F (5'-CGGAATGGCCGAGCAGATC -3') and inDS-B (5'-CAAGGTTTGGACCAGTTGCG-3'), which are specific for the 5'conserved segment containing integrase gene (intI 1) [19], were used to amplify this region by PCR. PCR with inDS-F and inDS-B primers did not yield amplicons for any of the 22 environmental isolates but yielded an $871 \mathrm{bp}$ amplicon for the clinical isolate 93LA5 as a positive control (Fig. 1).

Table 1. Antibiotic susceptibilities of V. cholerae isolates

\begin{tabular}{|c|c|c|c|c|c|c|c|c|c|c|c|}
\hline \multirow{2}{*}{ Strain ${ }^{*}$} & \multicolumn{9}{|c|}{$\operatorname{MIC}(\mu \mathrm{g} / \mathrm{ml})^{\S}$} & \multirow{2}{*}{ intI 1} & \multirow{2}{*}{ int $_{\mathrm{SXT}}$} \\
\hline & PMX & $\mathrm{TC}$ & AMP & AMP-CLA & EM & $\mathrm{NA}$ & $\mathrm{CP}$ & ST & SM & & \\
\hline $3 p-4$ & 0.4 & 0.8 & $>100$ & 0.4 & 3.13 & 0.1 & 0.8 & 10.0 & 12.5 & - & - \\
\hline $3 p-7$ & $>100$ & 0.2 & 6.25 & 1.6 & 12.5 & 0.2 & 1.6 & 10.0 & 6.25 & - & - \\
\hline $3 p-8$ & 0.4 & 0.2 & $>100$ & 0.4 & 12.5 & 0.1 & 0.8 & 5.0 & 12.5 & - & - \\
\hline $3 p-9$ & 0.4 & 0.2 & $>100$ & 0.8 & 12.5 & 0.1 & 0.8 & 5.0 & 12.5 & - & - \\
\hline $3 p-10$ & 0.4 & 0.2 & $>100$ & 0.8 & 12.5 & 0.2 & 0.8 & 5.0 & 12.5 & - & - \\
\hline $3 p-11$ & 0.4 & 0.2 & $>100$ & 0.4 & 12.5 & 0.2 & 0.8 & 5.0 & 12.5 & - & - \\
\hline $3 p-13$ & 0.4 & 0.2 & $>100$ & 0.4 & 12.5 & 0.2 & 0.8 & 5.0 & 12.5 & - & - \\
\hline $3 p-14$ & 0.4 & 0.2 & $>100$ & 0.8 & 12.5 & 0.2 & 0.8 & 5.0 & 12.5 & - & - \\
\hline $3 p-15$ & $>100$ & 0.4 & 6.25 & 3.13 & 12.5 & 0.2 & 1.6 & 10.0 & 6.25 & - & - \\
\hline $8 \mathrm{p}-2$ & 0.8 & 0.4 & $>100$ & 0.8 & 12.5 & 0.2 & 1.6 & 2.5 & 12.5 & - & - \\
\hline $11 \mathrm{pw}--2$ & 0.8 & 0.4 & $>100$ & 0.8 & 12.5 & 0.2 & 1.6 & 2.5 & 12.5 & - & - \\
\hline $12 \mathrm{pw}-2$ & 3.13 & 0.4 & $>100$ & 0.4 & 12.5 & 0.2 & 1.6 & 10.0 & 12.5 & - & - \\
\hline $12 \mathrm{pw}-3$ & 3.13 & 0.4 & $>100$ & 0.8 & 6.25 & 0.2 & 1.6 & 5.0 & 12.5 & - & - \\
\hline $12 \mathrm{pw}-4$ & 3.13 & 0.4 & $>100$ & 0.8 & 6.25 & 0.2 & 1.6 & 5.0 & 12.5 & - & - \\
\hline $12 \mathrm{pw}-6$ & 3.13 & 0.4 & $>100$ & 0.8 & 6.25 & 0.2 & 0.8 & 10.0 & 12.5 & - & - \\
\hline $12 \mathrm{pw}-7$ & 3.13 & 0.4 & $>100$ & 0.8 & 6.25 & 0.2 & 0.8 & 5.0 & 12.5 & - & - \\
\hline $12 \mathrm{cpw}-2$ & 1.6 & 0.2 & $>100$ & 0.8 & 6.25 & 0.2 & 0.8 & 5.0 & 6.25 & - & - \\
\hline $13 \mathrm{pw}-2$ & 1.6 & 0.4 & 6.25 & 1.6 & 25 & 0.2 & 0.8 & 40.0 & 12.5 & - & - \\
\hline $13 p w-3$ & 0.8 & 0.4 & 6.25 & 3.13 & 25 & 0.2 & 1.6 & 40.0 & 6.25 & - & - \\
\hline $13 p w-4$ & 1.6 & 0.8 & 6.25 & 3.13 & 25 & 0.2 & 1.6 & 40.0 & 6.25 & - & - \\
\hline $13 p w-5$ & 1.6 & 0.8 & 6.25 & 3.13 & 25 & 0.2 & 1.6 & 40.0 & 12.5 & - & - \\
\hline $13 \mathrm{pw}-7$ & $>100$ & 0.8 & $>100$ & 1.6 & 3.13 & 0.2 & 0.8 & 5.0 & 6.25 & - & - \\
\hline
\end{tabular}

* $\mathrm{p}$, strain recovered from peptone water with pyruvate; pw, strain recovered from peptone water without supplement; cpw, strain recovered from peptone water with catalase.

$\S$ Abbreviations: PMX, polymyxin B; TC, tetracycline; AMP, ampicillin; CLA, clavulanic acid; EM, erythromycin; NA, nalidixic acid; CP, chloramphenicol; ST, sulfamethoxazol-trimethoprim; SM, streptomycin. 


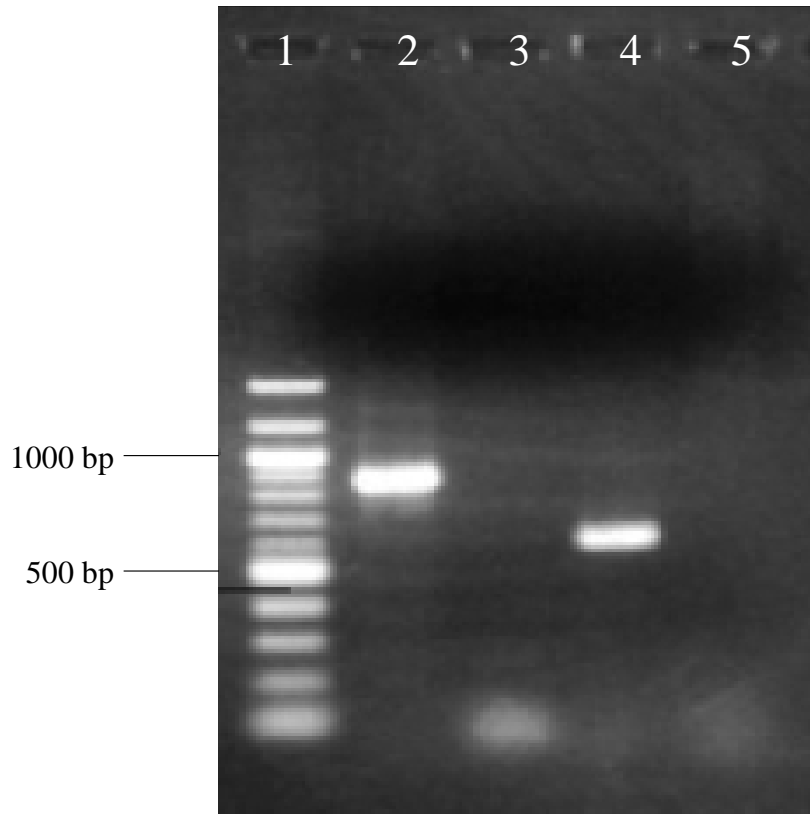

Fig. 1. Examples of PCR for the presence of class I integron using the primers inDS-F and inDS-B (lanes 2 and 3) and SXT element using primers INT1and INT2 (lanes 4 and 5) among $V$. cholerae non-O1, non-O139 strains isolated from Lao PDR. Lanes: 1,100-bp molecular mass standard; 2, strain 93LA5 (clinical isolate in 1993 harboring class I integron); 3 and 5, strain 3p-8 (environmental isolate); 4 , strain 00LA1 (clinical isolate in 2000 harboring SXT element).

SXT element is responsible for resistance to chloramphenicol, streptomycin, sulfamethoxazole and trimethoprim in $V$. cholerae [20]. Recently Hochhut et al. reported that deletion of the antibiotic resistance genes located on SXT element rendered these strains sensitive to the antibiotics [20]. We also noticed that $V$. cholerae O1 harboring SXT element were sensitive to all antibiotics examined, and in these strains, antibiotic resistant gene cluster was absent from the SXT element. All of the 22 isolates were sensitive to these four antibiotics, but we analyzed the possible presence of the SXT element backbone by PCR. Primers INT1 (5'-GCTGGATAGGTTAAGGGCGG-3') and INT2 (5'CTCTATGGGCACTGTCCACATTG-3'), which are specific for SXT integrase gene (int $t_{S X T}$ ) [20], were used. However, the expected 592 bp amplicon was not obtained from any of the environmental isolates (Fig. 1).

$V$. cholerae $\mathrm{O} 1$ and $\mathrm{O} 139$ are known to enter a viablebut-non-culturable (VBNC) state in the environment, and recovery of the non-culturable cells from samples relies on culture methods [21]. In this study, all environmental isolates were non-O1, non-O139 serotype isolated from samples by treatment with catalase or sodium pyruvate which enhance the recovery of non-culturable cells [14]. The fail- ure to detect $V$. cholerae $\mathrm{O} 1$ may have been due to their small population among a large number of non-O1 Vibrios. Therefore, further trials, such as immuno-magnetic separation technique using antibody against $V$. cholerae $\mathrm{O} 1$, are recommended.

The environmental non-O1, non-O139 isolates in this study showed resistance to polymyxin B and/or ampicillin. Resistance to these antibiotics was found to be common among the environmental non-O1, non-O139 isolates from Malaysia, Thailand and South India [2, 22, 23]. This result illustrates the occurrence of antibiotic-resistant environmental non-O1, non-0139 V. cholerae strains worldwide. However, it should be noted that environmental non-O1, non-O139 isolates clearly showed resistance to fewer antibiotics in comparison with clinical $V$. cholerae $\mathrm{O} 1$ isolates from Lao PDR [13]. In addition, there was a clear difference in distribution of class I integron and SXT element among clinical $\mathrm{O} 1$ isolates (unpublished observations) and environmental non-O1, non-O139 isolates from Lao PDR, as none of the environmental isolates harbored class I integron or SXT element. Thungapathra and colleagues [24] showed that multiple antibiotic resistances were more common among clinical isolates. Dalsgaard and colleagues reported that distribution of class I integron was associated with therapeutic use of antibiotics [25]. Thus, it seems unlikely that environmental non-O1, non-O139 isolates from Lao PDR are under antibiotic stress. In other words, the environmental waters examined are not contaminated with the organisms from a clinical origin.

The majority of ampicillin resistant $V$. cholerae contained plasmids and showed resistance to multiple antibiotics [8, 9, 23-25]. However, in Lao PDR, environmental isolates were resistant only to ampicillin without harboring plasmid, and $V$. cholerae $\mathrm{O} 1$ isolates from cholera patients were sensitive to ampicillin [12]. Class I integron and SXT element are occasionally lacking the drug resistance gene, but, they can acquire the resistance gene later. Therefore, Class I integron and SXT element should be monitored even in drug susceptible $V$. cholerae.

In the background of the present study, there is a fact that $V$. cholerae $\mathrm{O} 1$ in the world is simultaneously gaining resistant to a variety of anti-microbial drugs. There is a possibility that the transmission of SXT element takes place in the environmental water where $V$. cholerae consists of a flora, but this seems unlikely because we failed to find SXT element in the environmental $V$. cholerae. The transmission route of SXT element remains unclear.

\section{REFERENCES}

1 . Pitrak DL, Gindorf JD. Bacteremic cellulites caused by 
non-O1 Vibrio cholerae acquired in a freshwater inland lake. J Clin Microbiol 1989; 27: 2874-6.

2 . Radu S, Ho YK, Lihan S, et al. Molecular characterization of Vibrio cholerae $\mathrm{O} 1$ and non-O1 from human and environment sources in Malaysia. Epidimiol Infect 1999; 123: $225-32$.

3 . Mahalanabis D, Molla AM, Sack DA. Clinical management of Cholera. In: Barua D, Greenough WB III, eds. Chorela. New York: Plenum Medical, 1992; 253-83.

4 . Bag PK, Maiti S, Sharma C, et al. Rapid spread of the new clone of Vibrio cholerae O1 biotype El Tor in cholera endemic areas in India. Epidemiol Infect 1998; 121: 245-51.

5 . Dalsgaard, A., Forslund, A., Bodhidatta, L., et al. A high proportion of Vibrio cholerae strains isolated from children with diarrhea in Bangkok, Thailand are multiple antibiotic resistant and belong to heterogeneous non-O1, non-O139 O-serotypes. Epidemiol Infect 1999; 122: 217 26.

6 . Dupont M. J., Jouvenot M, Couetdic G, Michel-Briand Y. Development of plasmid-mediated resistance in Vibrio cholerae during treatment with trimethoprimsulfamethoxazole. Antimicrob Agents Chemother 1985; 27: $280-1$

7 . Reid AJ, Amyes GB. Plasmid penicillin resistance in $\mathrm{Vi}$ brio cholerae: identification of new $\beta$-lactamase SAR-1. Antimicrob Agents Chemother 1986; 30: 245-7.

8 . Young H, Nandivada LS, Amyes GB. Antibiotic resistance in the tropics. 1. The genetics bacterial ampicillin resistance in tropical areas. Trans R Soc Trop Med Hyg 1989; 83: 38-41.

9 . Dalsgaard A, Forslund A, Tam NV, Vinh DX, Cam PD. Cholera in Vietnam: changes in genotypes and emergence of class I integrons containing aminoglycoside resistance gene cassettes in Vibrio cholerae $\mathrm{O} 1$ strains isolated from 1979 to 1996. J Clin Microbiol 1999; 37: 734-41.

10 . Waldor MK, Tschäpe H, Mekalanos JJ. A new type of conjugative transposon encodes resistance to sulfamethoxazole, trimethoprim, and streptomycin in Vibrio cholerae O139. J Bacteriol 1996; 178: 4157-65.

11 . Higa N, Iwanaga M, Utsunomiya A, et al. Drug sensitivity of Vibrio cholerae and Shigella species in the world. Jpn J Trop Med Hyg 1995; 23: 159-64.

12. Phantouamath B, Sithivong N, Sisavath L, et al. Transition of drug susceptibilities of Vibrio cholerae O1 in Lao People's Democratic Republic. Southeast Asian J Trop Med Public Health 2001; 32: 95-9.

13. Iwanaga M, Toma C, Miyazato T, Insisiengmay S, Nakasone N, Ehara M. Antibiotic resistance conferred by a class I integron and SXT constin in Vibrio cholerae O1 strains isolated in Laos .Antimicrob Agents Chemother. 2004; 48: 2364-9.
14. Wai SN, Mizunoe Y, Takeda A, Yoshida S. A comparison of solid and liquid media for resuscitation of starvationand low-temperature-induced nonculturable cells of $A$ eromonas hydrophila. Arch Microbiol 2000; 173: 307-10.

15 . National Committee for Clinical Laboratory Standards. 2001. Methods for dilution antimicrobial susceptibility tests for bacteria that grow aerobically, 5th ed., Vol.20, no.2. Approved standerd M7-A5. National Committee for Clinical Laboratory Standers.

16. Kado CI, Liu ST. Rapid procedure for detection and isolation of large and small plasmids. J Bacteriol 1981; 145: 1365-73.

17 . Sasakawa C, Kamata K, Sakaki T, Murayama SY, Makino S, Yishikawa M. Molecular alteration of the 140megadalton plasmid associated with loss of virulence and congo red binding activity in Shigella flexneri. Infect Immun 1986; 51: 470-5

18. Mazel D, Davies J. Antibiotic resistance in microbes. Cell Mol Life Sci 1999; 56: 742-54.

19 . Dalsgaard A, Forslund A, Sandvang D, Arntzen L, Keddy K. Vibrio cholerae O1 outbreak isolates in Mozambique and South Africa in 1998 are multiple-drug resistant, contain the SXT element and the aadA2 gene located on class I integrons. J Antimicrob chemother 2001; 48: 82738.

20 . Hochhut B, Lotfi Y, Mazel D, Faruque SM, Woodgate R, Waldor MK. Molecular analysis of antibiotic resistance gene cluster in Vibrio cholerae O139 and O1 SXT constins. Antimicrob Agents Chemother 2001; 45: 29913000 .

21. Colwell RR, Brayton PR, Grimes DJ, Roszak DB, Huq SA, Palmer LM. Viable but non-culturable Vibrio cholerae and related pathogens in the environment: implication for release of genetically engineered microorganisms. Bio/Technology 1985; 3: 817-20.

22. Dalsgaard A, Serichantalergs O, Pitarangsi C, Echeverria P. Molecular characterization and antibiotic susceptibility of Vibrio cholerae non-O1. Epidemiol Infect 1995; 114: 51-63.

23. Thomson CJ, Jesudason MV, Balaji V, Malathi B, Mukundan U, Amyes SGB. The prevalence of Vibrio spp. in drinking water and environmental samples in Vellore South India. Epidemiol Infect 1998; 121: 67-76.

24 . Thungapathra M, Amita, Sinha KK, et al. Occurrence of antibiotic resistance gene cassettes aac (6')- $I b$, dfrA5, $d f r A 12$, and ereA2 in class I integrons in non-O1, nonO139 Vibrio cholerae strains in India. Antimicrob Agents Chemother 2002; 46: 2948-55.

25 . Dalsgaard A, Forslund A, Serichantalergs O, Sandvang D. Distribution and content of class I integron in different Vibrio cholerae O-serotype strains isolated in Thailand. Antimicrob Agents Chemother 2000; 44: 1315-21. 